\title{
The Relationship of Household Consumption, Investment and Economic Growth
}

\author{
Kunpeng Dai \\ Tianjin University of Finance and Economics, Tianjin, 300222, China
}

Keywords: simultaneous equation model; economic growth; investment; consumption

\begin{abstract}
This paper uses the data from 2000 to 2015 in our country, from the actual data of urban and rural investment and consumption, by establishing a simultaneous equation model, and analyzes the relationship of urban and rural investment, consumption and economic growth. The main conclusions show that although rural investment and consumption of buy-backs are relatively less, its pull function of investment and consumption to economic growth is bigger than urban pull function of investment and consumption, which provides theoretical basis for promoting China's economic growth.
\end{abstract}

\section{Introduction}

Since the 21st century, China's economy has grown rapidly and has become the world's second largest economy. Although the global financial crisis in 2008 has had various degrees of impact on our country and even on the world economy, after nearly 10 years of national macroeconomic regulation and control, we can still say that China's economy is facing the world in today's new normal economy. The economic situation plays a decisive role. Therefore, to explore the nature of economic growth is of far-reaching significance for understanding why the national economy stands for a long time in the forests of the nations of the world. At present, it is widely believed that stimulating domestic demand is the main method for promoting China's economic development. Domestic demand consists of consumer demand and investment. A reasonable and effective analysis of the relationship between the two is of great significance to the study of economic growth.

In recent years, domestic scholars have conducted research and analysis on this issue. Meng Hao used a linear regression approach in the article "Contrastive Analysis of the Contribution of Consumption and Investment to China's Economic Growth”[1], pointing out that consumption and investment will play an important role in China's economic development, and proposed that the level of consumption contributes more to economic development than The conclusion is greater investment. Li Zhanfeng's empirical analysis of China's data using the impulse response function in "China's consumption, investment, import, export, and economic growth"[2] confirms the above-mentioned effects of the troika on economic development, and that consumption is also one of the most important influencing factors. Ren Biyun pointed out in his article "Adjusting the Relationship between Investment and Consumption under the Binary Economic Structure”[3] that the difference between urban and rural areas in China is calculated by calculating the investment rate and consumption rate between urban and rural areas. The main reason affecting urban economic development is that consumption is to be treated. The main reason for the improvement of rural areas is that investment levels can continue to improve.

In China,domestic scholars in the study of this issue, some adopted the single equation model of research methods, the GDP as an explanatory variable, while the variables representing consumption, investment and other influencing factors on the right side of the equation as explanatory variables to explore their GDP Impact. You can't deny the irrationality of this method, but I think this method only studies the influence of unilateral influence. However, the network of economic systems in the real world is very large and 
all-encompassing. The relationship between economic variables is intricate and complex. If the neglect of the endogeneity relationship between variables will cause certain deviations in the quasi-determined model, it will eventually affect the research results on the issues. So I think the research method using the simultaneous equation model will be more accurate than the simple linear equation model. Although in recent years, the economic development has been accompanied by a small number of differences between urban and rural areas, the fact that China's vast and geographically diverse population does not distinguish between urban and rural areas when it comes to studying many economic issues may have a certain impact on the outcome. It is still undeniable that urban-rural duality is different. . If it does not distinguish between urban and rural areas, it will be detrimental to the formulation of policy proposals. So I think it is necessary to distinguish between urban and rural consumption and investment.

Therefore, based on the level of consumption and investment in urban and rural areas in China, this paper uses the data from 2000 to 2015 in China to establish a simultaneous simultaneous equation model for empirical analysis. The variable lag term is introduced into the model to reflect the dynamic effects of variables, and this model is used as a model. The analysis results are based on the corresponding recommendations.

\section{Variable Selection and Theoretical Model Design}

This article selects the gross national product (Y) from 2000 to 2015 as a variable indicating the level of economic development. It divides consumer expenditure into urban household consumption expenditure (C1) and rural household consumption expenditure (C2), using urban residents' fixed assets. The investment level represents the investment of urban residents (I1). Similarly, the investment level of rural residents represents the investment of rural residents (I2), and the government investment is denoted by $\mathrm{G}$. The variables $\mathrm{Y}, \mathrm{C} 1, \mathrm{C} 2$, I1, and I2 are used as the endogenous variables of the simultaneous equation model. The variable $G$ appears as an exogenous variable in the model.

After the rural-urban breakdown, the national income identities can be expressed as:

$$
Y_{t}=C_{1, t}+C_{2, t}+I_{1, t}+I_{2, t}+G_{t}
$$

Keynes's absolute income hypothesis [4] tells us that the current income level will affect people's current consumption level as an absolute influencing factor. Therefore, when the consumption equation is established in this paper, the current income level will be one of the explanatory variables. At the same time, people's consumption level in the real world tends to show a kind of inertia of consumption, so people will develop a kind of consumption inertia. Therefore, the model will use the previous level of consumption as one of the influencing factors. The established consumption equation is as follows:

$$
\begin{aligned}
& C_{1, t}=\alpha_{1}+\alpha_{2} C_{1, t-1}+\alpha_{3} Y_{t}+u_{1, t} \\
& C_{2, t}=\beta_{1}+\beta_{2} C_{2, t-1}+\beta_{3} Y_{t}+u_{2, t}
\end{aligned}
$$

In this paper, when we establish the investment equation, we can divide the investment into spontaneous investment and exogenous induced investment. Spontaneous investment is often caused by its own investment habits. In this paper, we can use the previous investment level to express this effect; exogenous investment is generally affected by changes in the economic environment in which investors are located. Therefore, we consider the changes in the previous period's income level as Explain the variables into the model. The investment equation established is as follows:

$$
I_{1, t}=\gamma_{1}+\gamma_{2} \Delta Y+\gamma_{3} I_{1, t-1}+u_{3, t}
$$




$$
I_{2, t}=\mu_{1}+\mu_{2} \Delta Y+\mu_{3} I_{2, t-1}+u_{4, t}
$$

Therefore, this article can establish a simultaneous equation model. The model is as follows:

$$
\left\{\begin{array}{c}
C_{1, t}=\alpha_{1}+\alpha_{2} C_{1, t-1}+\alpha_{3} Y_{t}+u_{1, t} \\
C_{2, t}=\beta_{1}+\beta_{2} C_{2, t-1}+\beta_{3} Y_{t}+u_{2, t} \\
I_{1, t}=\gamma_{1}+\gamma_{2} \Delta Y+\gamma_{3} I_{1, t-1}+u_{3, t} \\
I_{2, t}=\mu_{1}+\mu_{2} \Delta Y+\mu_{3} I_{2, t-1}+u_{4, t} \\
Y_{t}=C_{1, t}+C_{2, t}+I_{1, t}+I_{2, t}+G_{t}
\end{array}\right.
$$

After finishing the above formula, we can get the expression of gross national product. The expression is as follows:

$$
\begin{aligned}
& Y_{t}=\lambda_{0}+\lambda_{1} C_{1, t-1}+\lambda_{2} C_{2, t-1}+\lambda_{3} \Delta Y+\lambda_{4} I_{1, t-1}+\lambda_{5} I_{2, t-1}+\lambda_{6} G_{t}+u \\
& \lambda_{0}=\frac{\alpha_{1}+\beta_{1}+\gamma_{1}+\mu_{1}}{1-\alpha_{3}-\beta_{3}} \quad \lambda_{1}=\frac{\alpha_{2}}{1-\alpha_{3}-\beta_{3}} \\
& \lambda_{2}=\frac{\beta_{2}}{1-\alpha_{3}-\beta_{3}} \quad \lambda_{3}=\frac{\gamma_{2}+\mu_{2}}{1-\alpha_{3}-\beta_{3}} \\
& \lambda_{4}=\frac{\gamma_{3}}{1-\alpha_{3}-\beta_{3}} \quad \lambda_{5}=\frac{\mu_{3}}{1-\alpha_{3}-\beta_{3}} \\
& \lambda_{6}=\frac{1}{1-\alpha_{3}-\beta_{3}}
\end{aligned}
$$

\section{Empirical Results Analysis}

\subsection{Data.}

The data in this paper are from the China Economic and Social Development Statistics Database and China Statistical Yearbook 2016. e selected variables are the gross domestic product (Y) of expenditure from 2000 to 2015, the annual total consumption of urban and rural residents (C1 and $C 2$ ), government expenditure $(G)$, and the fixed asset investment of urban and rural residents (I1, I2).In order to facilitate the following modeling calculation process, we will use the consumer price index to process the data $(2000$ year $=100)$, and the investment data will be converted using the fixed asset investment price index.

\subsection{Model parameter estimation results.}

Using the statistical software Eviews6.0 to estimate the simultaneous equation model using the two-stage least square method, the expression of the resulting consumption equation is as follows:

$$
\begin{aligned}
& C_{1, t}=-387.77+0.67 C_{1, t-1}+0.12 Y_{t}+u_{1, t} \\
& \bar{R}^{2}=0.9994 \quad D W=1.92 \\
& C_{2, t}=2129.50+0.55 C_{2, t-1}+0.04 Y_{t}+u_{2, t} \\
& \bar{R}^{2}=0.9942 \quad D W=1.75
\end{aligned}
$$

From the expression of the consumption equation, we can see that for every $1 \mathrm{RMB}$ increase in income level, the consumption levels of urban and rural residents increase by 0.12 
and 0.04 RMB respectively; and for every 1 RMB increase in consumption in the previous period, the consumption levels of urban and rural residents will increase by 0.67 RMB and $0.55 \mathrm{RMB}$ respectively. RMB. It can be seen that the impact of consumption habits on residents' consumption in the short term will be greater than the impact of income on consumption, and the influence of consumption habits of urban residents will be greater than that of rural residents. Therefore, in order to continue to promote economic growth, we must continue to promote consumption, especially the consumption of rural residents. The government should continue to improve the rural residents' security system, improve the living standards of rural residents, and cultivate rural residents' consumption habits.

The estimated investment equation is as follows:

$$
\begin{aligned}
& I_{1, t}=6031.67+0.406 \Delta Y+0.88 I_{1, t-1}+u_{3, t} \\
& \bar{R}^{2}=0.9963 \quad D W=1.06 \\
& I_{2, t}=5697.37+0.039 \Delta Y+0.49 I_{2, t-1}+u_{3, t} \\
& \bar{R}^{2}=0.2612 \quad D W=1.80
\end{aligned}
$$

From the expression of the investment equation, we can see that the amount of change in the previous period's income level will have a significant impact on the investment level of urban and rural residents, and that the degree of impact on the level of investment of urban residents has been greatly improved compared with rural residents. In addition, the level of investment is affected by the level of investment in the previous period, which means that urban residents are more than twice as rural residents. This is in contrast to the ability of rural residents to bear the investment risk is worse than that of urban residents. In addition, the level of investment in the previous period for the urban investment in the current period is about twice the level of change in income, and it will be greatly changed for rural residents.

Since this article is intended to study the impact of investment and consumption on economic growth, we can estimate the expression (7) mentioned above. The estimated results are as follows:

$$
\begin{aligned}
& Y_{t}=76286.14+2.15 C_{1, t-1}+5.24 C_{2, t-1}+0.76 \Delta Y+0.85 I_{1, t-1}+1.58 I_{2, t-1}+8.4 G_{t}+u \\
& \bar{R}^{2}=0.994 \quad D W=2.49
\end{aligned}
$$

The per capita consumption level of urban residents and rural residents increased by RMB 1 and the output level increased by RMB 2.15 and RMB 5.24 in the current period. However, for each increase of RMB 1 in the previous period, the current output level increased by RMB 0.85 and RMB 1.58 respectively. It can be seen that consumption and investment levels will have a certain role in promoting economic growth. Observe that rural residents' consumption investment is greater than the urban economy in the pull of investment; whether it is urban residents or rural residents, the level of consumption of the economy will always be greater than the driving role of investment in the economy.

\section{Conclusion and Suggestion}

The current problem in China at this stage is that the absolute value of rural consumption and investment is less than that of towns. Therefore, when formulating policies, we should treat different regions differently, stabilize the scale of urban development in areas with better urbanization, and enable the region to maintain its existing economic vigor. In places where urbanization is relatively backward, we should vigorously improve the local area. Various safeguard systems have enabled the majority of farmers to earn income from the original single plantation of crops and slowly develop into a multi-income mixed society. From the aspects of medical education, etc., they solve the worries of farmers and increase 
their sense of well-being. The quality of life of the majority of farmers has been improved, and their consumption and investment levels have naturally improved. At the same time, economic growth will also play a certain role in increasing the level of consumption and investment of residents.

All in all, the problems existing in China at this stage can be understood as the low investment in rural areas and the increase in the income of farmers. It can be said that rural areas play an important role in the growth of China's economy. Therefore, we should focus on increasing the income of farmers, trying every means to improve the living standards of our country's peasants, and further improve their consumption and investment capabilities, and at the same time promote the healthy development of China's economy.

\section{References}

[1] H. Meng. A Comparative Analysis of the Contribution of Consumption and Investment to China's Economic Growth [J]. Productivity Research, 2006, 11:22 23.(In Chinese)

[2] Z.F. Li. Consumption, Investment, Import, Export, and Economic Growth in China [J].Statistical Research, 2009, 2:39 42. (In Chinese)

[3] B.Y. Ren. On the adjustment of the relationship between investment and consumption in the dual economic structure [J]. Modern Economy, 2009, 2:8 12.

[4] J.C. Chang. An Analysis of the Contribution of Investment, Consumption, and Export to China's Economic Growth from the Perspective of Keynesian Economic Theory [J]. Herald Tribune, 2012, 13: 4 5. (In Chinese) 